\title{
Serious eye injury in badminton players
}

\author{
S P KELLY
}

From the Department of Ophthalmology, Leicester Royal Infirmary, Leicester LE1 5WW

SUMMARY Serious eye injury can occur in badminton players and may become more frequent. The causes and nature of such injuries in this sport in six patients are discussed. All were playing competitive doubles matches. Penetrating eyé injury due to a shattered glass spectacle lens occurred. Players should be advised not to wear spectacles with glass lenses. Ocular protection in this sport is desirable, and the forward player should hold the racket in front of the face.

The ophthalmologist's role in reporting the hazards to the eye in various sports is increasingly important. ${ }^{1}$ Ocular injuries in ice hockey and squash have generated a considerable literature and preventive measures have been advised in those games. ${ }^{2-5}$ Eye injuries in badminton have been reported by Chandran in Malaysia, ${ }^{6-7}$ with a peak during the 1970 Thomas Cup. Blonstein, ${ }^{8}$ who has been associated with squash and badminton sports medicine since 1946 , reported that 'on the whole serious eye injuries are extremely rare in badminton'.

Six serious eye injuries from badminton play are reported here in the hope of encouraging better ocular protection in this popular sport.

\section{Subjects and methods}

Six patients with eye injuries from playing badminton were examined by the author at the Leicester Royal Infirmary. All were local amateur players. One other patient, who sustained an injury in India from a shuttlecock causing retinal detachment, is not included, though he was treated in this hospital. Four patients sustained their injuries in 1985 and were seen in the acute phase. Case 3 sustained injury in 1982, case 6 in 1979; both stillrequire outpatient treatment.

\section{Results}

Table 1 gives the age, sex, nature of ocular injury, and most recent visual acuity. Table 2 records the details of play when injury occurred. Three patients needed surgery; the others have been treated con-

Correspondence to Mr S P Kelly, FRCSEd, Manchester Royal Eye Hospital, Oxford Road, Manchester M13 9WH. servatively. All were experienced players, playing doubles at a competitive level. Only case 1 wore spectacles. All had at least $6 / 6$ Snellen corrected vision in the uninvolved eye.

Table 1. Clinical details of patients

\begin{tabular}{|c|c|c|c|c|c|}
\hline Case & Age & $\operatorname{sex}$ & Eye & Injury & $\begin{array}{l}\text { Most } \\
\text { recent VA }\end{array}$ \\
\hline 1 & 35 & $\mathbf{M}$ & $\mathbf{L}$ & $\begin{array}{l}\text { Corneoscleral perforation, uveal } \\
\text { prolapse, glass intraocular FB }\end{array}$ & $6 / 9$ \\
\hline 2 & 61 & $\mathbf{F}$ & $\mathbf{L}$ & Hyphaema, sphincter pupillae tear & $6 / 9$ \\
\hline 3 & 20 & $\mathbf{F}$ & $\mathbf{R}$ & Retinal dialysis and detachment & $6 / 9$ \\
\hline 4 & 16 & $\mathbf{M}$ & $\mathbf{R}$ & $\begin{array}{l}\text { Hyphaema, choroidal rupture } \\
\text { involving macula }\end{array}$ & CF \\
\hline 5 & 30 & $\mathbf{M}$ & $\mathbf{R}$ & $\begin{array}{l}\text { Angle recession glaucoma, } \\
\text { vitreous haemorrhage }\end{array}$ & LP \\
\hline 6 & 56 & $\mathbf{M}$ & $\mathbf{R}$ & $\begin{array}{c}\text { Hyphaema, angle recession } \\
\text { glaucoma, optic atrophy }\end{array}$ & $6 / 9$ \\
\hline
\end{tabular}

$\mathrm{FB}=$ foreign body. $\mathrm{CF}=$ counting fingers at $0 \cdot 3 \mathrm{~m} . \mathrm{LP}=$ perception of light only.

Table 2 Sports injury details

\begin{tabular}{lll}
\hline Case & Injury & $\begin{array}{l}\text { No of years playing } \\
\text { badminton }\end{array}$ \\
\hline 1 & $\begin{array}{c}\text { Partner's racket broke player's glass } \\
\text { spectacles }\end{array}$ & 30 \\
2 & $\begin{array}{c}\text { Hit by opponent's shuttlecock, smash } \\
\text { stroke at net }\end{array}$ & 40 \\
3 & $\begin{array}{c}\text { Hit by opponent's shuttlecock, smash } \\
\text { stroke at net }\end{array}$ & 6 \\
4 & $\begin{array}{c}\text { Hit by opponent's shuttlecock, smash } \\
\text { stroke at net }\end{array}$ & 5 \\
5 & $\begin{array}{c}\text { Hit by partner's shuttlecock, smash } \\
\text { stroke while turning to face him }\end{array}$ & 12 \\
6 & $\begin{array}{c}\text { Hit by opponent's shuttlecock, smash } \\
\text { stroke at net }\end{array}$ & 20 \\
\hline
\end{tabular}

All players were playing competitive doubles matches. 


\section{Discussion}

Badminton results in few injuries, mostly minor, such as cramps, blisters, and sprains. ${ }^{9}$ Only $6 \%$ of all injuries are due to the shuttlecock and $7 \%$ to the racket. ${ }^{9}$ These rarer direct injuries are often to the eye and may be severe, as shown in this series. Serious ocular injury is recognised in ice hockey, ${ }^{2}$ squash rackets, ${ }^{3-5}$ tennis, ${ }^{10}$ and golf, ${ }^{1}$ but no previous report of perforating eye injury in badminton was found in the literature. Badminton is a very popular sport and often played in schools. The vision in case 4 , a schoolboy aged 16 , is permanently and severely reduced.

None of these players wore eye protection. Case 1, who was wearing spectacles with glass lenses, was under the false impression that they provided some protection. Had he been wearing toughened, plastic lenses when hit he might have been spared such serious injury. Four patients were injured while close to the net by a shuttlecock from the opponent's smash hit. This type of injury also occurs in tennis players who 'rush the net'. ${ }^{10}$ Badminton players and coaches should be aware of this risk in aggressive doubles competitions. The forward player should hold the racket in front of the face while awaiting the return stroke, particularly if a high lob has been delivered, when a smash return is probable. Eye and facial injuries from the shuttlecock may thus be prevented.

Ocular injury rates requiring outpatient treatment in the Southampton study from shuttlecocks were in fact higher than the squash ball injury rates. Severer injuries requiring inpatient treatment occurred there more often from squash. ${ }^{4}$ Badminton players can now achieve greater shuttlecock velocities by using steel framed rackets with carbon fibre shafts than previously possible with the older wooden rackets according to a former badminton coach (Warner J, personal communication). Given these advances in racket technology and a higher outpatient injury ratio, it is probable that more cases of serious eye injury will occur in this sport. This small cluster of six serious eye injuries in this hospital from badminton may signify a trend if players continue to play without protecting their eyes.

Vinger recommends that all racket players wear eye protection and describes the appropriate products available.' Uniocular players should be especially mindful of this advice. In addition, prescribers of spectacles should advise badminton players to wear toughened plastic lenses in sturdy spectacle frames. A shattered glass spectacle lens in sport causing serious eye injury may have possible medicolegal implications to the spectacle prescriber as well as being a preventable cause of blindness.

I acknowledge with gratitude the advice given to me by badminton players. I thank the consultants at the Leicester Royal Infirmary for allowing me to report on patients under their care.

\section{References}

1 Vinger PF. The eye and sports medicine. In: Duane TD, Jaeger EA, eds. Clinical opthalmology. Philadelphia: Harper and Row, 1985; 5: Ch.45: 1-51.

2 Pashby TJ, Pashby RC, Chisholm LDJ. Eye injuries in Canadian hockey. Can Med Assoc J 1978; 118: 298-305.

3 Ingram DV, Lewkonia I. Ocular hazards of playing squash rackets. Br J Ophthalmol 1973; 57: 663-6.

4 Barrell GV, Cooper PL, Elkington AR, MacFadyen JM, Powell RG, Tormey P. Squash ball to eye ball: the likelihood of squash players incurring an eye injury. Br Med J 1981; 283: 893-5.

5 Bankes KJL. Squash rackets; a survey of eye injuries in England. Br Med J 1985; 291: 1539.

6 Chandran S. Ocular hazards of playing badminton. $B r J$ Ophthalmol 1974; 58: 757-60.

7 Chandran S. Hyphema and badminton injuries. Med J Malaysia 1972; 26: 207-10.

8 Blonstein JL. Eye injuries in sport: with particular reference to squash rackets and badminton. Practitioner 1975; 215: 208-9.

9 Hensley LD, Paup DC. A survey of badminton injuries. Br J Sports Med 1979; 13: 156-60.

10 Seelanfruend MH, Freilich DB. Rushing the net and retinal detachment. JAMA 1976; 235: 2723-5.

11 Millar CT. Golfing eye injuries. Am J Ophthalmol 1967; 64: 741.

Accepted for publication 31 October 1986. 